World Lumen Congress 2021 | May 26-30, 2021 |

Iasi, Romania

\title{
The Role of Donations in Financing Extreme Risk Events
}

\author{
Ionela-Daniela GĂITAN (BOTEZATU)
}

https://doi.org/10.18662/wlc2021/23

How to cite: Găitan-Botezatu, I.-D. (2021). The Role of Donations in Financing Extreme Risk Events. In A. Sandu (vol. ed.), Lumen Proceedings: Vol. 17 World Lumen Congress 2021 (pp. 217-227). Iasi, Romania: LUMEN Publishing House. https://doi.org/10.18662/wlc2021/23 


\title{
The Role of Donations in Financing Extreme Risk Events
}

\author{
Ionela-Daniela GĂITAN (BOTEZATU) ${ }^{1}$
}

\begin{abstract}
Globally, post-event funding needs are growing, while the material and human damage caused by extreme events is constantly growing. The 2015 United Nations (UN) Global Assessment Report on Disaster Risk Reduction estimated that worldwide, these extreme events cause losses of approximately \$250-300 billion annually.

Although there are now various post-event financing options (insurance, grants, loans, donations, etc.) for the population, companies or public institutions, these instruments are often not sufficient for post-event recovery and reconstruction, so many challenges remain for post-event recovery.

Thus, there is often a gap between the financing needs of companies or the population and the existing financing instruments, most often the amounts needed for financing being higher than the amounts that are available through the various existing financing mechanisms.

In this article we addressed the topic of post-event funding sources such as donations and highlighted that these, although they are one of the cheapest sources of funding, the support of post-event donors is often uncertain.

Also, in the elaboration of this paper I used qualitative and quantitative research based on the use of methods such as Spearman correlation indicator, data processing and analysis, documenting reports, studying reference works and other studies.
\end{abstract}

Keywords: Donations, financing, risk, extreme events, correlation.

\section{Introduction}

Extreme risk events have led to the loss of lives and livelihoods, destroyed infrastructure, businesses and buildings, and reconstruction and recovery after such events can take years.

The analysis of extreme risk events found that much research has been done in the natural sciences to help predict extreme events and prepare the population to increase resilience to them, but economic research on these events and their consequences are limited.

Financial risk analysis helps government representatives make informed decisions and make effective use of disaster risk financing strategies and tools.

\footnotetext{
${ }^{1}$ PhD Student, "Ştefan cel Mare” University of Suceava, Romania. ionela danielag@yahoo.com
} 
In order to adopt an effective strategy in case of natural disasters, it is recommended to use combined funding instruments, both planned before and after the event.

\section{Conceptual approaches on the donations - post-event planned financing instrument}

The donor community (financial institutions, international agencies, nongovernmental organizations and donor governments) believes that should be done more to promote risk reduction investment through a pre-disaster system than through a post-disaster fundraising system. Thus, instead of waiting to be asked to fund postdisaster organizations could use the funds to finance the planning, preparation and implementation of coordinated disaster response default, as described in the response and recovery plan. However, there is less recognition of the need to support risk collection and transfer programs that provide funds available immediately after the disaster for relief and reconstruction (Linnerooth-Bayer et al., 2005).

NGOs play an important role in the first part of post-event recovery, using donations to support especially the health field, which is often down to earth due to the negative effects of extreme risk events.

International aid is a crucial force when a health disaster collapses following a natural disaster and the health system needs to recover as soon as possible (for example, the Leogane health system has not worked, following the earthquake in Haiti in 2010, and the aid financed 12 out of 13 new healthcare units that opened after the earthquake, as well as the reconstruction of 7 out of 8 healthcare units) (Kligerman et al., 2015).

The richest countries don't need as much assistance as poor, even if extreme risk events in rich regions (for example the 2011 tsunami in Japan), can create needs which provoke international aid. The main needs for poor countries for disaster relief are usually water, sanitation, food and shelter. Extreme risk events like natural disasters, unlike armed conflicts, involves need for emergency aid which is not very long (Leaning et al., 2013).

An increase in donated amounts does not necessarily mean that they will significantly improve the results of recovery and reconstruction, because the resources from donations are limited and unpredictable. For this reason, governments cannot rely solely on this financial instrument when planning a response to an extreme risk event.

At the same time, this instrument for financing extremely risky events supports the government's response only if these events occur very rarely and in isolation, being less effective when events occur frequently or have negative effects globally (such as pandemics).

In some low-income countries, the number of donors involved in disaster response could be high, and the most important for them is to know how long it takes to mobilize and obtain these funds. For example, in Myanmar, in the period 1990-2010, donor assistance commitments to finance extreme events such as disasters amounted to 
\$ 723 million, with $96 \%$ of these donations representing emergency allocations. The main donors were the European Community (25\%), the United Kingdom (13\%), the United States (15\%), Norway (8\%) and Australia (8\%) (DRFIP, 2017).

The humanitarian system is made up of organizations that use only the resources at their disposal, funds collected voluntarily from governments and the population, with an unspecified contribution. They also do not have large budgets that can be used in case of emergency.

The largest requests for funding come from poor countries, which turn directly to international organizations to support them in the event of extreme risk events, an approach that leads to an uneven funding process. Such a funding model, based on donations, is not recommended because it creates ambiguity about the actors who must act in the event of an extreme risk event, who is exposed to the risk and who is responsible for financing it.

The use of financial instruments such as donations creates ambiguity about who is at risk, who will have to act and who will have to pay for it. Both governments and various United Nations agencies, such as the United Nations High Commissioner for Refugees (UNHCR), the World Food Program (WFP), the World Health Organization (WHO), the United Nations Children's Fund (UNICEF) and the United Nations Office for the Coordinator of Humanitarian Affairs (OCHA), as well as various large donors, will claim to take risks so that appropriate responses and funding materialize, but there is no guaranteed funding to deliver on the promises, so a model to deliver funds when something happen is needed.

An example of an extreme risk event in which it was not clear who was responsible for risk management was the Ebola outbreak in 2014. For this reason, the response to the event was delayed. In the event of this, the situation was of the opinion that national governments should take the risk, as has been done in the management of previous outbreaks of Ebola, and WHO should contribute to government assistance by providing a layer of protection against risk, if governments needed help (Clarke \& Dercon, 2016). Even though they have experienced previous outbreaks, this time neither national governments nor WHO have managed to manage the pandemic. Also, donors did not plan the steps to be taken in such situations, not being prepared to provide a rapid response to the extreme risk event. Due to these impediments, the long period in which no action was taken led to increased costs for managing the epidemic. Although donor funding is the cheapest source of funding after an extreme risk event, and many donors offer clearly established humanitarian programs, these funds also have limitations. One such limitation is media coverage, which makes donor assistance more difficult (an example would be the catastrophic floods that occurred in 2005 in Guyana, which were not widely publicized and had limited international assistance because they occurred at a shortly after the great earthquake in Pakistan). Another example of limiting donations is the mobilization of funds and their payment, a laborious process that can take a long time. Donations made after an event involve an opportunity cost because it involves changing the default schedule.

Finally, with limited resources, donors are rarely able to support larger 
reconstruction programs. Experts recommend that governments in developing countries not rely solely on the generosity of their donor partners (Ghesquiere \& Mahul, 2010).

Resource mobilization after an extreme event must also have mechanisms in place to execute these resources, as resources are often readily available, but many steps must be taken before they can be used (for example, in some countries obtaining a loan is necessary a parliamentary approval, a long procedure).

In order to be able to observe how long it takes to obtain funds, simulations can be made, which have the role of helping to identify the bottlenecks in this risk financing process.

\section{Aims of the research and the methods used}

This article aims to identify the role of the donations in financing extreme risk events and to emphasize the need for a financial strategy when an extreme risk event occurs, as the cheapest sources of funding, such as donations, cannot always be accessed when we need to.

The aim of this paper is to identify the relationship between donations, the cheapest source of financing extreme risk events and the magnitude of the coronavirus pandemic, starting from the hypothesis that in the case of extreme risk events that produce global effects, external funding (donations) do not have a direct relationship with the magnitude of the pandemic (most funds are not directed to the most affected countries).

In the elaboration of this paper was used the method of empirical theory, Spearman correlation indicator, data processing and analysis, documenting reports, studying reference works and other studies.

So, I started the study from the hypothesis that in the case of extreme risk events that produce global effects (for example coronavirus pandemic), donations do not have a direct relationship with the magnitude of the pandemic.

In this paper was used Spearmen correlation indicator for to determine whether there is a link between the amount of donations received by countries affected by the coronavirus pandemic and the cases of people confirmed with Covid-19 registered.

Data required for the donation analysis were retrieved from the United Nations Office for the Coordination of Humanitarian Affairs (OCHA, 2020) and data for people confirmed with the new coronavirus were retrieved from the WHO (World Health Organization, 2021b) website.

\section{Analysis of the impact of donated funds on mitigating the negative effects of the spread of the coronavirus pandemic in European countries}

The hypothesis of the study is that donated funds are not directly correlated with the magnitude of the coronavirus pandemic, which is why governments should 
not rely solely on such funds in pandemic management.

In this analysis, we applied the Spearman correlation coefficient to identify whether there is a link between the magnitude of the pandemic and the sources of funding such as donations.

Correlation analysis is an analysis of the measurement of correlation and direction on the linear relationship between two variables in probability theory and statistics. Both variables can have an independent relationship or are correlated. The correlation means the intensity of the relationship between two variables (Song \& Park, 2019).

The Spearman correlation coefficient does not need data scaled over an interval, it is non-parametric (assumptions about the normality of variables are not made), there must not be a linear relationship between the two variables, but the relationship must have a direction.

The limits of the Spearman coefficient are that ordinal data or interval data are needed, in the samples there must not be many orders that are too close and we must assume that the relationship has a direction.

Molnar (2020) used the Spearman correlation coefficient in a retrospective analysis to determine whether the magnitude of disasters in the period 2000-2010 (measured by total deaths) is directly correlated with donated funds. This hypothesis was confirmed after conducting the study. Thus, it turned out that over a period of about six years, funding had a significant and moderate inverse relationship with the mortality rate $(p=0.0139)$. It did not find significant relationships between funding and infrastructure or labor in this analysis. He also pointed out that major natural disasters attract more donations and are more likely to disrupt society for a longer period of time, likely affecting the mortality rate.

For the initial sample, data were analyzed and collected from an international database that includes all climatic, hydrological, extraterrestrial, meteorological and geophysical disasters, from 2000-2010, being excluded from the sample biological disasters such as epidemics, because they are often followed by non-biological disasters and can cause confusion (Molnar, 2020).

This sample was refined due to constraints caused by the absence of data from the WHO Global Health Observatory and UNOCHA Financial Monitoring Service (FTS) data repository(World health organization, 2021a).

In this study, it was analyzed whether the committed and paid funding received by NGOs to play a role in the results of the post-disaster recovery. Variables were chosen to address mortality (overall mortality rate and maternal mortality rate), infrastructure (access to sanitation, drinking water infrastructure) and medical staff (doctors per 10,000 inhabitants). Variables were selected to reflect pre-disaster (one year before event), and post-disaster (five years after event) settings. The six-year interval between these variables was necessary to measure the long-term recovery response. The data referred to 40 natural disasters and were analyzed with Stata, a software used in statistics and based on the Spearman correlation coefficient.

There were weak correlations between total donated funding and labor, 
medical labor and infrastructure.

But in this analysis, it was shown that funding, in all categories, had a significant relationship with the mortality rate. Namely, it was found that while the funds increase, there is also an increase in the mortality rate. One explanation for this relationship could be that larger disasters, with a higher number of deaths, are more likely to affect the long-term mortality rate and disrupt a country's health.

As the severity and frequency of natural disasters increase, they contribute to increasing socio-economic and healthcare disparities, leading to a global crisis and public health.

The limitations of this study are the general lack of data, the lack of data transparency and the limited sample size, which significantly weaken the results of this analysis.

In some studies, it has been shown that about 3\% of the total estimated economic losses in the event of an extreme risk event can be covered by donations. It has also been shown that the value of donations does not depend on donor strategies or political factors. The amount of donations could depend on the intensity of the extreme risk event itself and the degree of development of the country in which it takes place, the reserves it has or the size of the country (Becerra et al., 2014).

Authors such as Song and Park (2019) conducted a study in which they presented a damage prediction formula, using a multiple regression model. In order to develop the damage prediction formula, they used in their study economic indicators from 1900-2017 and the amount of damage caused by natural disasters in 187 countries around the world.

Thus, they used as independent variables of the damage prediction formula the population, area and level of GDP in each country, and using the correlation coefficients Spearman, Kendall and Pearson, identified positive correlations between economic losses, GDP and population, losses of human lives, affected people and population(Organisation for economic co-operation and development, 2020).

To perform this analysis we divided the selected countries into clusters.

Clustering was performed using SPSS 25 using $\mathrm{K}$ means clusters. The 20 countries included in the research were grouped into 3 clusters based on the number of confirmed cases per 100,000 inhabitants and based on the number of deaths/ 100,000 inhabitants, occurring following Covid-19 infection. Belonging to one of the clusters is illustrated in the table below.

Table 1. Cluster members

\begin{tabular}{cccc}
\hline $\begin{array}{c}\text { No. } \\
\text { crt. }\end{array}$ & Country & Cluster & Distance \\
\hline 1 & Spain & 1 & 80,191 \\
2 & Italy & 1 & 156,749 \\
3 & Romania & 3 & 95,625 \\
4 & Greece & 3 & 140,020 \\
5 & Bulgaria & 3 & 13,313 \\
6 & Croatia & 3 & 56,402
\end{tabular}




\begin{tabular}{cccc}
7 & Cyprus & 3 & 89,749 \\
8 & Ukraine & 3 & 15,713 \\
9 & Serbia & 3 & 117,326 \\
10 & Republic of Moldova & 1 & 68,226 \\
11 & Albania & 3 & 28,364 \\
12 & Armenia & 2 &, 000 \\
13 & Azerbaidjan & 3 & 143,809 \\
14 & Belarus & 1 & 163,506 \\
15 & Bosnia and Herzegovina & 1 & 167,362 \\
16 & Georgia & 3 & 154,954 \\
17 & Kazakhstan & 1 & 28,921 \\
18 & Montenegro & 1 & 15,799 \\
19 & Northern Macedonia & 1 & 8,263 \\
20 & Turkey & 3 & 85,209 \\
\hline
\end{tabular}

Source: own elaboration with the help of the program SPSS 25.

From the table above it can be seen that in the first cluster there are 8 countries, namely: Spain, Italy, Republic of Moldova, Belarus, Bosnia and Herzegovina, Kazakhstan, Montenegro, Northern Macedonia. In the second cluster there is only Armenia and in cluster 3 there are 11 countries (Romania, Greece, Bulgaria, Croatia, Cyprus, Ukraine, Serbia, Azerbaijan, Georgia, Turkey).

Table 1. Number of countries in each cluster

\begin{tabular}{l|rcc}
\hline \multirow{3}{*}{ Cluster } & 1 & 8 \\
& 2 & 1 \\
& 3 & 11 \\
\hline \multirow{3}{*}{ Valid } & 20 \\
& Missing & 0 \\
\hline
\end{tabular}

Source: own elaboration with the help of the program SPSS 25

In the first cluster, the countries register an average of 563.7 cases per 100,000 inhabitants and a number of 24.86 deaths per 100,000 inhabitants. In cluster 2, is just Armenia, the number of confirmed cases per 100,000 inhabitants is 1,356 cases and the number of deaths is 26.5 people per 100,000 inhabitants. Cluster 3, which has 11 countries, has on average the lowest number of confirmed cases per 100,000 inhabitants of 185.4 cases and the lowest number of deaths of 4,836 per 100,000 inhabitants. 


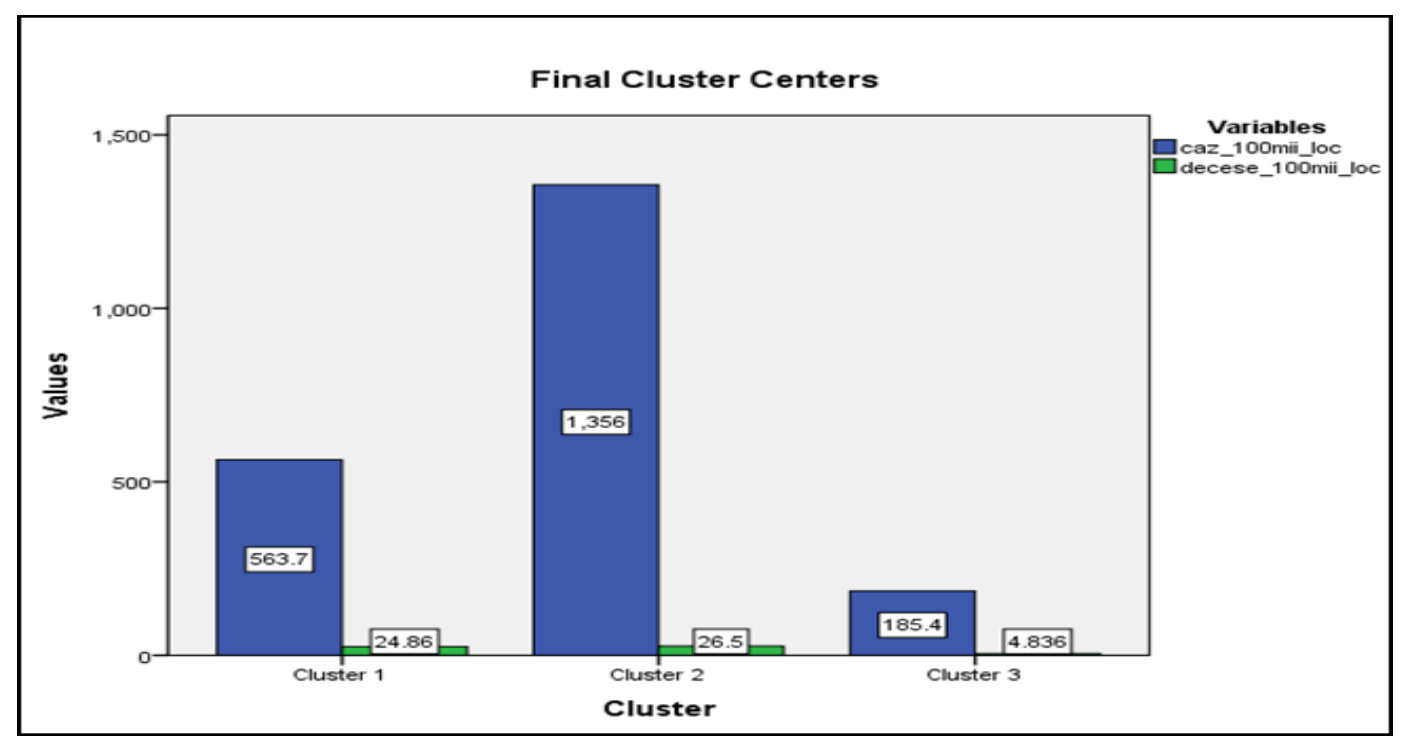

Fig. 1. Average cases in clusters

Source: own elaboration with the help of the program SPSS 25.

The distance from cluster 1 to cluster 2 is 792.439 and from cluster 3 is 378.801. Between cluster 2 and cluster 3 is a distance of 1170,910 , as can be seen from the centralized data in the following table.

Table 2. The distance between the central environments of the clusters

\begin{tabular}{cccc}
\hline Cluster & $\mathbf{1}$ & $\mathbf{2}$ & $\mathbf{3}$ \\
\hline 1 & & 792,439 & 378,801 \\
2 & & 1170,910 \\
3 & & \\
\hline
\end{tabular}

Source: own elaboration with the help of the program SPSS 25

Next, I performed a correlation analysis to identify the link between donations and cases confirmed by Covid/ deaths.

The correlation analysis performed using the Spearman coefficient shows that there is no correlation between the number of confirmed cases per 100,000 inhabitants and the funding performed. We can make the same statement about the number of deaths per 100,000 inhabitants and funding. 
Table 3. Correlations between funding and Covid cases, respectively deaths

\begin{tabular}{|c|c|c|c|c|c|c|c|}
\hline & & & $\begin{array}{l}\text { Case/10 } \\
0,000 \\
\text { inhabita } \\
\text { nts }\end{array}$ & $\begin{array}{c}\text { Deaths/ } \\
100,000 \\
\text { inhabita } \\
\text { nts }\end{array}$ & $\begin{array}{c}\text { Ext fin } \\
\text { ang } \\
\text { donation } \\
s \\
\end{array}$ & $\begin{array}{c}\text { Ext fin } \\
\text { gov }\end{array}$ & $\begin{array}{l}\text { Fin } \\
\text { ong }\end{array}$ \\
\hline \multirow{15}{*}{$\begin{array}{l}\text { Spear } \\
\text { man's } \\
\text { rho }\end{array}$} & \multirow{3}{*}{$\begin{array}{l}\text { case_100,0 } \\
\text { 00_inhabit } \\
\text { ants }\end{array}$} & $\begin{array}{l}\text { Correlat } \\
\text { ion }\end{array}$ & 1,000 &, $794^{* *}$ &,- 165 &,- 093 &,- 068 \\
\hline & & Sig. & . & ,000 & ,486 & ,698 & ,776 \\
\hline & & $\mathrm{N}$ & 20 & 20 & 20 & 20 & 20 \\
\hline & \multirow{3}{*}{$\begin{array}{l}\text { deaths_100 } \\
\text {,000_- } \\
\text { inhabitants }\end{array}$} & $\begin{array}{l}\text { Correlat } \\
\text { ion }\end{array}$ & & 1,000 &,- 152 & ,038 &,- 107 \\
\hline & & Sig. & & . & ,523 & ,874 & ,654 \\
\hline & & $\mathrm{N}$ & & 20 & 20 & 20 & 20 \\
\hline & \multirow{3}{*}{$\begin{array}{l}\text { ext_fin_an } \\
\text { g_donation } \\
\text { s }\end{array}$} & $\begin{array}{l}\text { Correlat } \\
\text { ion } \\
\end{array}$ & & & 1,000 &, $582^{* *}$ &, $889^{* *}$ \\
\hline & & Sig. & & & . & ,007 & ,000 \\
\hline & & $\mathrm{N}$ & & & 20 & 20 & 20 \\
\hline & \multirow{3}{*}{$\begin{array}{l}\text { ext_fin_go } \\
\mathrm{v}\end{array}$} & $\begin{array}{l}\text { Correlat } \\
\text { ion }\end{array}$ & & & & 1,000 & ,313 \\
\hline & & Sig. & & & & 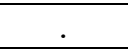 & , 179 \\
\hline & & $\mathrm{N}$ & & & & 20 & 20 \\
\hline & \multirow{3}{*}{ fin_ong } & $\begin{array}{l}\text { Correlat } \\
\text { ion } \\
\end{array}$ & & & & & 1,000 \\
\hline & & Sig. & & & & & . \\
\hline & & $\mathrm{N}$ & & & & & 20 \\
\hline
\end{tabular}

**. Correlation is significant at the 0.01 level (2-tailed).

Source: own elaboration with the help of the program SPSS 25

This limited analysis does not seek to criticize post-disaster funding or relief efforts, but rather encourages their use in conjunction with other financial instruments, with the chosen strategy requiring evidence-based responses.

\section{Conclusions and discussions}

This article complements international studies on the sources of funding that can be used in the event of extreme risk events.

Internationally, there are many bibliographic resources on extreme risk events themselves and how they can be managed, but very few refer to the financing part of the events. In order to reduce the economic impact of extreme risk events, it is important to focus on the financing side of the events from the prevention phase.

Donations are the cheapest sources of funding. In the event of an extremely isolated risk event, most funds from charities or donor countries go to that event, with a significant impact on the expenditure needed to help, recover and rebuild. 
The problem arises when multiple extreme risk events occur simultaneously or an extreme risk event that produces negative effects globally because funds are limited and, once directed to a particular event, will take a period of time to what new funds will be attracted that can be used.

This can also be seen in the case of the coronavirus pandemic. Following the analysis carried out in European countries, it can be seen that the donations were not distributed according to the magnitude of the pandemic in different countries.

For this reason, in the event of extremely risky events, countries need to rely on financial strategies to act quickly, including other sources of funding, such as reserve funds, emergency loans, insurance, etc., even if they involve additional costs.

A risk financing strategy in a country refers to the development of the government's capacity to respond after the occurrence of an extreme event, while protecting the fiscal balance. In order to build such strategies, countries have a number of financial instruments at their disposal, each with its own costs and other advantages and disadvantages.

We cannot say that one financial instrument is better than another, because an effective financial strategy against extreme events is based on a combination of these financial instruments, depending on the country's fiscal risk profile and the cost of available instruments.

In implementing such a strategy, it is also necessary to focus on the existing legal and administrative framework, which ensures that the proposed financial instruments can be used effectively following an extreme event to mitigate the impact on the economy and the population (Worldometer, 2021).

Post-event financing is a complex process through the multitude of actors involved in the post-event recovery process and the fiscal risks assumed.

Post-event financial instruments have their limits, so post-event donor support is often uncertain, government-created reserves are limited by other urgent needs or political considerations, and the amount of emergency credit is limited by borrowing capacity of a country (for example, the case of small countries with high debt levels and limited borrowing capacity). Also, while emergency reserves and appropriations can be used for several purposes (in compliance with budgetary laws), aid obtained through donations is often offered in kind (food or aid materials).

In developing countries insurance and other capital market instruments have not been sufficiently developed so far, in these countries a small part of the economic losses caused by disasters have been insured. For this reason, in these countries these financial instruments can be encouraged to be used, given that extreme events put great pressure on donors and government resources.

\section{References}

Becerra, O., Cavallo, E., \& Noy, I. (2014). Foreign aid in the aftermath of large natural disasters. Review of Development Economics, 18(3), 445-460. https://dx.doi.org/10.1111/rode.12095 
Clarke, D., \& Dercon, S. (2016). Dull Disasters? How planning ahead will make a difference. Oxford University Press.

DRFIP. (2017). Disaster Risk Finance Country Diagnostic Note: Myanmar. World Bank Disaster Risk Financing and Insurance Program. https://www.financialprotectionforum.org/sites/default/files/DRFI_Myanmar_0. pdf

Ghesquiere, F., \& Mahul, O. (2010). Financial Protection of the State against Natural Disaster, The World Bank Latin American and the Carribean Region Finance and Private Sector Development Sustainable Development Network. Policy Research Working Paper. https://openknowledge.worldbank.org/handle/10986/3912?show=full

Kligerman, M., Barry, M., Walmer D., \& Bendavid, E. (2015). International aid and natural disasters: A pre-and post-earthquake longitudinal study of the healthcare infrastructure in Leogane, Haiti. American Journal of Tropical Medicine and Hygiene, 92(2), 448-453. https://doi.org/10.4269/ajtmh.14-0379

Leaning, J., \& Guha-Sapir, D. (2013). Natural disasters, armed conflict, and public health. New England Journal of Medicine, 369(19), 1836-1842. https://doi.org/10.1056/NEJMra1109877

Linnerooth-Bayer, J., Mechler, R., \& Pflug, G. (2005). Refocusing Disaster Aid. Science Journal, 309(5737), 1044-1046. https://doi.org/10.1126/science.1116783

Molnar, E. (2020). Natural Disaster Recovery: a preliminary analysis of 21st century relief funding in natural disasters and its relation to long-term recovery outcomes. [Unpublished doctoral dissertation, University of Arizona College of Medicine]. Repository Arizona Edu. https://repository.arizona.edu/bitstream/handle/10150/641621/SP 2020 Molna $\underline{r}$ Thesis.pdf?sequence $=7$

Song, Y. S., \& Park, M. J. (2019). Development of damage prediction formula for natural disasters considering economic indicators. Sustainability, 11, 868, https://doi.org/10.3390/su11030868

World Health Organization. (2021a). Global Health Observatory data repository. World Health Organization. https://apps.who.int/gho/data/node.main.HWFGRP 0020?lang=en

World Health Organization. (2021b). WHO Coronavirus (COVID-19) Dashboard. World Health Organization. https://covid19.who.int/

OCHA Services. (2020). Coronavirus disease Outbreak- COVID-19 2020. FTS.UNOCHA https://fts.unocha.org/emergencies/911/summary/2020

Organisation for economic co-operation and development. (2020). Quarterly National Accounts: G20 - Quarterly Growth Rates of GDP in volume. OECD. Stat. https://stats.oecd.org/index.aspx?queryid $=33940$

Worldometer. (2021). Current World Population. Worldometer. https://www.worldometers.info/world-population/ 